Friedman Shareholder of: AbbVie Inc, Employee of: AbbVie Inc, Jose Jeffrey Enejosa Shareholder of: AbbVie, Employee of: AbbVie, Stephen Hall Grant/ research support from: Abbvie, UCB, Janssen, Merck, Eduardo Mysler Grant/ research support from: AbbVie, Amgen, Bristol Myers Squibb, Roche, Eli Lilly, Novartis, Janssen, Sanofi, and Pfizer., Speakers bureau: AbbVie, Amgen, Bristol Myers Squibb, Roche, Eli Lilly, Novartis, Janssen, Sanofi, and Pfizer, Patrick Durez Speakers bureau: AbbVie, Bristol-Myers Squibb, Celltrion, Eli Lilly, Pfizer, Sanofi, Xenofon Baraliakos Grant/research support from: Grant/research support from: AbbVie, BMS, Celgene, Chugai, Merck, Novartis, Pfizer, UCB and Werfen, Consultant of: AbbVie, BMS, Celgene, Chugai, Merck, Novartis, Pfizer, UCB and Werfen, Speakers bureau: AbbVie, BMS, Celgene, Chugai, Merck, Novartis, Pfizer, UCB and Werfen, Tim Shaw Shareholder of: AbbVie, Employee of: AbbVie, Yanna Song Shareholder of: AbbVie Inc., Employee of: AbbVie Inc., Yihan Li Shareholder of: AbbVie, Employee of: AbbVie, In-Ho Song Shareholder of: AbbVie Inc., Employee of: AbbVie Inc.

DOI: 10.1136/annrheumdis-2020-eular.1869

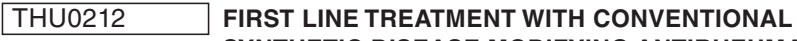 SYNTHETIC DISEASE MODIFYING ANTIRHEUMATIC DRUGS IN RHEUMATOID ARTHRITIS: A MULTINATIONAL POPULATION-BASED COHORT FROM 14 REAL WORLD HEALTHCARE DATABASES AND 9 COUNTRIES - REALITY VERSUS GUIDELINES}

A. G. Sena ${ }^{1}$, D. Granados ${ }^{2}$, N. Hughes ${ }^{3}$, W. Fakhouri ${ }^{4}$, A. Hottgenroth ${ }^{5}$, R. Kolde ${ }^{6}$, S. Reisberg ${ }^{7}$, C. O. Torre ${ }^{8}$, T. Duarte-Salles ${ }^{9}$, Y. Díaz ${ }^{10}$, J. F. Golib-Dzib ${ }^{11}$, E. S. Brouwer ${ }^{12}$, E. Burn ${ }^{13}$, J. Lane ${ }^{14}$, D. Vizcaya ${ }^{15}$, S. Bruce Wirta $^{16}$, M. De Wilde ${ }^{17}, \mathrm{~K}$. Verhamme ${ }^{18}$, P. Rijnbeek ${ }^{19}$, E. Theander ${ }^{20}$, K. Chatzidionysiou ${ }^{21}$, D. Prieto-Alhambra ${ }^{22}$, P. Ryan ${ }^{12,23}$ on behalf of 'European Health Data and Evidence Network (EHDEN) RA Research Group: ' Janssen Research And Development, New Jersey, United States of America; ${ }^{2}$ Sanofi Aventis Group, Chilly-Mazarin, France; ${ }^{3}$ Janssen Europe, Middle East and Africa, Beeres, Belgium; ${ }^{4}$ Eli Lilly and Company, Erl Wood, Windlesham, Surrey, United Kingdom; ${ }^{5}$ Lilly Deutschland GmbH, Homburg, Germany; ${ }^{6}$ Institute of Computer Science, University of Tartu, Tartu, Estonia; ${ }^{7}$ Institute of Computer Science of University of Tartu, Tartu, Estonia; ${ }^{8}$ Real-World Solutions, IQVIA, London, United Kingdom; ${ }^{9}$ Fundació Institut Universitari per a la Recerca a I'Atenció Primària de Salut Jordi Gol i Gurina (IDIAPJGol), Barcelona, Spain; ${ }^{10}$ Fundació Institut Universitari per a la Recerca a I'Atenció Primària de Salut Jordi Gol i Gurina (IDIAPJGol), Barcelona, Spain; ${ }^{11}$ Real World Evidence Market Access Department Janssen-Cilag, Madrid, Spain; ${ }^{12}$ Janssen Europe, Middle East and Africa, New Jersey, United States of America; ${ }^{13}$ Fundació Institut Universitari per a la Recerca a I'Atenció Primària de Salut Jordi Gol i Gurina (IDIAPJGol), Barcelona, Spain; ${ }^{14}$ Centre for Statistics in Medicine (CSM), Nuffield Department of Orthopaedics, Rheumatology and Musculoskeletal Sciences, University of Oxford, Oxford, United Kingdom; ${ }^{15}$ Epidemiology, Bayer, Barcelona, Spain; ${ }^{16}$ Janssen EMEA, New Jersey, United States of America; ${ }^{17}$ Department of Medical Informatics, Erasmus MC, Rotterdam, Netherlands; ${ }^{18}$ Department of Medical Informatics, Erasmus MC, Rotterdam, Netherlands; ${ }^{19}$ Department of Medical Informatics, Erasmus MC, Rotterdam, Netherlands; ${ }^{20}$ Janssen Europe, Middle East and Africa, New Jersey, United States of America; ${ }^{21}$ Dep of Medicine, Solna, Rheum Unit, Karolinska Institutet, Stockholm, Sweden; ${ }^{22}$ University of Oxford, Centre for Statistics in Medicine (CSM), Nuffield Department of Orthopaedics, Rheumatology and Musculoskeletal Sciences, Oxford, United Kingdom; ${ }^{23}$ Observational Health Data Sciences and Informatics, New York, United States of America

Background: Treatment guidelines recommend early initiation of csDMARDs following diagnosis of rheumatoid arthritis (RA), with methotrexate (MTX) as firstline therapy. Scarce evidence exists on adherence to this guidance

Objectives: To characterize first-line csDMARD treatment during the first year following an RA diagnosis.

Methods: 14 real world databases (3 Primary care, 6 primary/secondary care records, 5 claims) from 9 countries were included, all mapped to the OMOP common data model.

Patients were included on the earliest event of: 1st diagnosis of RA or 1st DMARD prescription with an RA diagnosis within 30 days. Patients were $>18$ years-old, required $1+$ year pre-index data, and at least 1-year follow-up. Study period covered 2000-2018. Previous users of DMARDs or non-RA inflammatory arthritis history were excluded. Only MTX, Hydroxychloroquine (HCQ), Sulfasalazine (SSZ) and Leflunomide (LEF) were available in all databases.

Results: We identified 323,547 eligible participants. Large variation was observed internationally (Figure 1). MTX as first-line monotherapy ranged from $33.3 \%$ to $74.5 \%$, and in combination with $\mathrm{HCQ}$ from $2.1 \%$ to $6.7 \%$. Three additional csDMARDs were used as first-line: HCQ in $10.1 \%$ to $30.2 \%$, SSZ in $0.9 \%$ to $28.7 \%$, and LEF in $1.8 \%$ to $15.2 \%$.

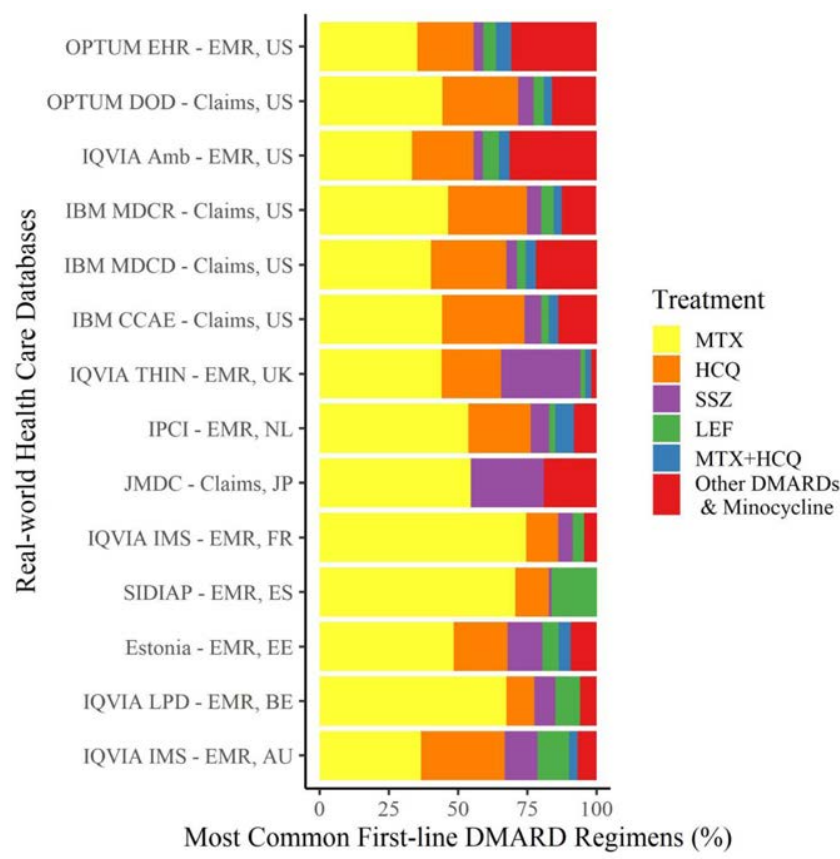

Figure 1. First line csDMARD treatment during 1yr from first observed RA diagnosis

Conclusion: We report wide heterogeneity of first-line csDMARDs regimens internationally. Despite recommendations for MTX to be first line therapy, data suggest that a large proportion of patients receive alternative csDMARD.

Disclosure of Interests: : Anthony G Sena Shareholder of: J\&J shares, Grant/ research support from: Full-time employment salary from Janssen, Consultant of: Full-time employment salary from Janssen, Employee of: Janssen employee, Paid instructor for: Janssen employee, Speakers bureau: Janssen employee, Denis Granados: None declared, Nigel Hughes Shareholder of: J\&J shares, Grant/research support from: Full-time employment salary from Janssen, Consultant of: Janssen employee, Employee of: Janssen employee, Paid instructor for: Janssen employee, Speakers bureau: Janssen employee WALID FAKHOURI Shareholder of: E Lilly Shares, Employee of: Eli Lilly and Company, Antje Hottgenroth Shareholder of: Eli Lilly shares, Employee of: Lilly Deutschland GmbH, Raivo Kolde: None declared, Sulev Reisberg: None declared, Carmen Olga Torre: None declared, Talita Duarte-Salles: None declared, Yesika Díaz: None declared, Jose Felipe Golib-Dzib Grant/research support from: Full-time employment salary from Janssen, Employee of: Yes, Janssen employee, Paid instructor for: Janssen Employee, Speakers bureau: Janssen Employee, Emily S. Brouwer Shareholder of: J\&J shares, Takeda shares, Grant/research support from: Full-time employment salary from Janssen, Consultant of: Janssen employee, Employee of: Janssen employee, Paid instructor for: Janssen Employee, Speakers bureau: Janssen Employee, Edward Burn: None declared, Jennifer Lane: None declared, David Vizcaya Employee of: Bayer, Sara Bruce Wirta Employee of: Janssen-Cilag Sweden AB, Marcel de Wilde: None declared, Katia Verhamme: None declared, Pete Rijnbeek: None declared, Elke Theander Employee of: Janssen-Cilag Sweden AB, Katerina Chatzidionysiou Consultant of: AbbVie, Pfizer, Lilly., Danie Prieto-Alhambra Grant/research support from: Professor Prieto-Alhambra has received research Grants from AMGEN, UCB Biopharma and Les Laboratoires Servier, Consultant of: DPA's department has received fees for consultancy services from UCB Biopharma, Speakers bureau: DPA's department has received fees for speaker and advisory board membership services from Amgen, Patrick Ryan: None declared

DOI: 10.1136/annrheumdis-2020-eular.3131

\section{THU0213 UPADACITINIB AS MONOTHERAPY IN PATIENTS WITH RHEUMATOID ARTHRITIS AND PRIOR INADEQUATE RESPONSE TO METHOTREXATE: RESULTS AT 84 WEEKS FROM THE SELECT- MONOTHERAPY STUDY}

J. S. Smolen ${ }^{1}$, P. Emery ${ }^{2}$, W. Rigby ${ }^{3}$, Y. Tanaka ${ }^{4}$, J. Ignacio Vargas ${ }^{5}$, N. Damjanov ${ }^{6}$, M. Jain ${ }^{7}$, Y. Song ${ }^{8}$, N. Khan ${ }^{8}$, J. J. Enejosa ${ }^{8}$, S. B. Cohen ${ }^{9}$ ${ }^{1}$ Medical University of Vienna, Vienna, Austria; ${ }^{2}$ University of Leeds \& 
NIHR Biomedical Research Centre, Leeds, United Kingdom; ${ }^{3}$ Dartmouth College, Hanover, United States of America; ${ }^{4}$ University of Occupational and Environmental Health, Kitakyushu, Japan; ${ }^{5}$ Quantum Research, Puerto Varas, Chile; ${ }^{6}$ University of Belgrade School of Medicine, Institute of Rheumatology, Belgrade, Serbia; ${ }^{7}$ Great Lakes Clinical Trials, Chicago, United States of America; ${ }^{8}$ AbbVie, Inc, North Chicago, United States of America; ${ }^{9}$ Metroplex Clinical Research Center, Dallas, United States of America

Background: In the SELECT-MONOTHERAPY trial, upadacitinib (UPA), an oral JAK inhibitor, demonstrated significantly greater efficacy compared to continuing methotrexate (MTX) when used as monotherapy over 14 weeks (wks) in patients (pts) with rheumatoid arthritis (RA) and prior inadequate response to MTX.

Objectives: To describe the long-term safety and efficacy of UPA monotherapy in an ongoing long-term extension (LTE) of the SELECT-MONOTHERAPY trial.

Methods: Pts on stable MTX were randomized to either continue MTX (cMTX, given as blinded study drug) or switch to once-daily (QD) UPA 15 (UPA15) or 30 (UPA30) mg monotherapy for 14 wks. From Wk14, pts could enter a blinded LTE and continue to receive UPA15 or UPA30; pts randomized to CMTX were switched to UPA15 or UPA30 per pre-specified assignment at baseline. Treatment-emergent adverse events (TEAEs) per 100 pt yrs (PYs) of exposure are summarized up to a cut-off data of 5 February 2019, when all pts had reached Wk84. Efficacy outcomes through Wk84 are reported as observed and using non-responder imputation

Results: Of 648 pts randomized, 598 (92\%) completed 14 wks and entered the LTE on blinded UPA. By the cut-off date, $20 \%$ in total had discontinued due to the following: $A E(6 \%)$, consent withdrawal (4\%), lost to follow-up $(2 \%)$, lack of efficacy $(1 \%)$, or other reasons $(7 \%)$. Cumulative exposures were 421.5 and 425.9 PYs for UPA15 and UPA30, respectively. The most frequently reported TEAEs were urinary tract infection, creatine phosphokinase (CPK) increase, upper respiratory tract infection, nasopharyngitis, worsening of RA, bronchitis, herpes zoster $(\mathrm{HZ})$, and alanine aminotransferase increase; the most common serious AE was pneumonia. Events of $\mathrm{HZ}$, hepatic disorder, and CPK elevations were higher among pts receiving UPA30, while rates of serious infection and malignancy appeared comparable between doses (Figure). Most $\mathrm{HZ}$ events involved 1-2 dermatomes, with a single disseminated cutaneous event (UPA30) and none with CNS involvement. Five patients experienced MACE, and there were 5 VTE events (UPA15: 4; UPA30: 1). All MACE and VTE events occurred in pts with underlying risk factors. Pts continuing to receive UPA 15 and UPA30 achieved stringent endpoints at Week 84 (Table). Pts who switched from cMTX to UPA15 or UPA30 demonstrated comparable efficacy responses to those initially randomized to UPA.

Conclusion: The adverse event profile associated with long-term exposure to UPA 15 or 30 as monotherapy was consistent with an integrated analysis of UPA safety across the entire phase 3 program, with no new safety signals identified. Further, UPA15 or 30 monotherapy resulted in continued and sustained improvements in RA signs and symptoms through 84 wks.

References:

[1] Smolen, et al. Lancet 2019;393(10188):2303-11.

Figure. Treatment-emergent Adverse Events Through $\geq 84$ Weeks (E/100 PYs, 95\% Cl).

\begin{tabular}{|c|c|c|}
\hline \multicolumn{2}{|l|}{ Event } & $\begin{array}{l}\text { E/100 PYs } \\
(95 \% \mathrm{Cl})\end{array}$ \\
\hline Serious AE & $\mapsto$ & $\begin{array}{l}18.5(14.6,23.1) \\
16.9(13.2,21.3)\end{array}$ \\
\hline \multirow{2}{*}{ AE leading to $D / C$ of study drug } & $\mapsto$ & $7.8(5.4,11.0)$ \\
\hline & $\mapsto$ & $9.9(7.1,13.3)$ \\
\hline \multirow{2}{*}{ Serious infection } & $\longmapsto$ & $4.7(2.9,7.3)$ \\
\hline & & $4.2(2.5,6.7)$ \\
\hline \multirow{2}{*}{ Opportunistic infection } & $=$ & $0.7(0.1,2.1)$ \\
\hline & $\longmapsto$ & $1.9(0.8 .3 .7)$ \\
\hline Herpes zoster & $\longmapsto$ & $4.3(2.5,6.7)$ \\
\hline \multirow{2}{*}{ Hepatic disorder } & $\mapsto$ & $8.0(4.8,10.1)$ \\
\hline & $\mapsto$ & $12.2(9.1,16.0)$ \\
\hline \multirow{2}{*}{ Malignancy (excl. NMSC) } & $\longmapsto$ & $1.2(0.4,2.8)$ \\
\hline & $\longrightarrow$ & $\frac{0.9(0.3,2.4)}{0(0.0)}$ \\
\hline NMSC & 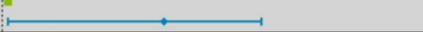 & $0.2(0.0,1.3)$ \\
\hline \multirow{2}{*}{ MACE (adjudicated) } & $\Longrightarrow$ & $0.5(0.1,1.7)$ \\
\hline & $\longmapsto$ & $1.2(0.4,2.7)$ \\
\hline VTE (adjudicated) & $\rightleftarrows$ & $0.9(0.3,2.4)$ \\
\hline \multirow{3}{*}{ Death } & & $\frac{0.2(0.0 .1 .3)}{0.7(0.1 .2 .1)}$ \\
\hline & $\longrightarrow$ & $0.7(0.1,2.1)$ \\
\hline & 0.1 & 50 \\
\hline \multicolumn{3}{|c|}{ E/100PYs (95\% Cl) } \\
\hline $\begin{array}{l}\text { UPA } 15 \mathrm{mg}, \mathrm{N}=318(421.5 \\
\text { PYs) }\end{array}$ & $\begin{array}{l}\text { A } 15 \mathrm{mg}, \mathrm{N}=318(421.5 \\
\text { s) }\end{array}$ & $(425.9$ \\
\hline
\end{tabular}

Table. Proportion of Patients at Week 84

\begin{tabular}{|c|c|c|c|c|c|c|c|c|}
\hline \multirow[t]{2}{*}{ Parameter (\%) } & \multicolumn{2}{|c|}{ 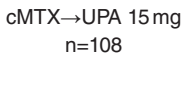 } & \multicolumn{2}{|c|}{$\begin{array}{c}\mathrm{cMTX} \rightarrow \text { UPA } \\
30 \mathrm{mg} \\
\mathrm{n}=108\end{array}$} & \multicolumn{2}{|c|}{$\begin{array}{l}\text { UPA } 15 \mathrm{mg} \\
\quad \mathrm{n}=217\end{array}$} & \multicolumn{2}{|c|}{$\begin{array}{l}\text { UPA } 30 \mathrm{mg} \\
\qquad \mathrm{n}=215\end{array}$} \\
\hline & $\mathrm{AO}$ & NRI & $\mathrm{AO}$ & NRI & $\mathrm{AO}$ & NRI & $\mathrm{AO}$ & NRI \\
\hline ACR20/50/70 & $86 / 71 / 49$ & $67 / 56 / 39$ & $90 / 68 / 50$ & $66 / 51 / 38$ & $88 / 71 / 5$ & $65 / 53 / 41$ & $96 / 78 / 667$ & $74 / 62 / 52$ \\
\hline $\begin{array}{c}\text { DAS28(CRP) } \\
\leq 3.2 /<2.6\end{array}$ & $80 / 56$ & $64 / 44$ & $79 / 63$ & $62 / 49$ & $76 / 60$ & $57 / 46$ & $85 / 77$ & $67 / 61$ \\
\hline $\mathrm{CDAl} \leq 10 / \leq 2.8$ & $78 / 38$ & $62 / 30$ & $85 / 29$ & $65 / 22$ & $74 / 34$ & $55 / 25$ & $85 / 49$ & $67 / 39$ \\
\hline Boolean Remission & 27 & 22 & 23 & 18 & 26 & 20 & 41 & 33 \\
\hline
\end{tabular}

$\mathrm{AO}$, as observed; NRI, non-responder imputation.

Disclosure of Interests: : Josef S. Smolen Grant/research support from: AbbVie, Eli Lilly, Janssen, Merck Sharp \& Dohme, Pfizer, Roche - grant/research support, Consultant of: AbbVie, Amgen Inc., AstraZeneca, Astro, Celgene Corporation, Celtrion, Eli Lilly, Glaxo, ILTOO, Janssen, Medimmune, Merck Sharp \& Dohme, Novartis, Pfizer, Roche, Samsung, Sanofi, UCB - consultant, Speakers bureau: AbbVie, Amgen Inc., AstraZeneca, Astro, Celgene Corporation, Celtrion, Eli Lilly, Glaxo, ILTOO, Janssen, Medimmune, Merck Sharp \& Dohme, Novartis, Pfizer, Roche, Samsung, Sanofi, UCB - speaker, Paul Emery Grant/research support from: AbbVie, Bristol-Myers Squibb, Merck Sharp \& Dohme, Pfizer, Roche (all paid to employer), Consultant of: AbbVie (consultant, clinical trials, advisor), Bristol-Myers Squibb (consultant, clinical trials, advisor), Lilly (clinical trials, advisor), Merck Sharp \& Dohme (consultant, clinical trials, advisor), Novartis (consultant, clinical trials, advisor), Pfizer (consultant, clinical trials, advisor), Roche (consultant, clinical trials, advisor), Samsung (clinical trials, advisor), Sandoz (clinical trials, advisor), UCB (consultant, clinical trials, advisor), William Rigby Grant/research support from: Bristol-Myers Squibb, Consultant of: AbbVie, Bristol-Myers Squibb, Genentech, Pfizer, Yoshiya Tanaka Grant/research support from: Asahi-kasei, Astellas, Mitsubishi-Tanabe, Chugai, Takeda, Sanofi, Bristol-Myers, UCB, Daiichi-Sankyo, Eisai, Pfizer, and Ono, Consultant of: Abbvie, Astellas, Bristol-Myers Squibb, Eli Lilly, Pfizer, Speakers bureau: Daiichi-Sankyo, Astellas, Chugai, Eli Lilly, Pfizer, AbbVie, YL Biologics, Bristol-Myers, Takeda, Mitsubishi-Tanabe, Novartis, Eisai, Janssen, Sanofi, UCB, and Teijin, Juan Ignacio Vargas Consultant of: AbbVie, Nemanja Damjanov Grant/research support from: from AbbVie, Pfizer, and Roche, Consultant of: AbbVie, Gedeon Richter, Merck, Novartis, Pfizer, and Roche, Speakers bureau: AbbVie, Gedeon Richter, Merck, Novartis, Pfizer, and Roche, Manish Jain Grant/research support from: AbbVie, Novartis, Celgene, Medac, and Takeda, Speakers bureau: AbbVie, Novartis, Celgene, Medac, and Takeda, Yanna Song Shareholder of: AbbVie Inc., Employee of: AbbVie Inc., Nasser Khan Shareholder of: AbbVie Inc., Employee of: AbbVie Inc., Jose Jeffrey Enejosa Shareholder of: AbbVie, Employee of: AbbVie, Stanley B. Cohen Grant/research support from: Amgen, Abbvie, Boehringer Ingelheim, Pfizer and Sandoz, Consultant of: Amgen, Abbvie, Boehringer Ingelheim Pfizer and Sandoz

DOI: 10.1136/annrheumdis-2020-eular.961

\section{THU0214 LONG-TERM EFFECTIVENESS OF METHOTREXATE WITH STEP DOWN GLUCOCORTICOID BRIDGING (COBRA SLIM) VERSUS OTHER CONVENTIONAL DMARD REGIMENS AS INITIAL RA THERAPY: 5-YEAR OUTCOMES OF THE CARERA TRIAL.}

V. Stouten ${ }^{1}$, R. Westhovens ${ }^{1,2}$, D. De Cock ${ }^{1}$, S. Pazmino ${ }^{1}$, J. Joly ${ }^{2}$, D. Bertrand ${ }^{1}$, K. Van der Elst ${ }^{1,2}$, P. Verschueren ${ }^{1,2}$ on behalf of CareRA Study Group. ${ }^{1} \mathrm{KU}$ Leuven, Skeletal Biology and Engineering Research Center, Department of Development and Regeneration, Leuven, Belgium; ${ }^{2}$ University Hospitals Leuven, Rheumatology, Leuven, Belgium

Background: The treat-to-target Care in Early Rheumatoid Arthritis (CareRA) trial demonstrated that remission induction with csDMARD combinations and step-down glucocorticoids (GCs) was not superior over methotrexate (MTX) monotherapy with step-down GCs (Cobra Slim) in RA patients with a high-risk profile (1). Moreover, Cobra Slim showed benefit over a tight step-up with MTX in monotherapy (TSU) in RA patients with a low-risk profile.

Objectives: To compare the long term outcomes up to 5 years of different initial intensive treatment strategies in participants of the CareRA-plus study.

Methods: In the CareRA trial, patients with DMARD naïve early RA were stratified in a high- or low-risk group based upon the presence of serummarkers, disease activity and erosive status. High-risk patients were randomised to Cobra Classic (MTX+sulphasalazine with highly dosed GC remission induction scheme), Cobra Avant-Garde (MTX+leflunomide with moderately dosed GC scheme) or Cobra Slim. Low-risk patients were randomised to Cobra Slim or TSU. Patients completing this trial were eligible for the CareRA-plus observational study. Here, patients were evaluated 6-monthly over 3 years. Therapy adaptation was left to the treating physician. Efficacy was assessed by DAS28-CRP and HAQ and compared between the originally allocated treatment arms. The 5-year evolution 